\title{
PREVALENCE OF TRACHOMA IN THAR DESERT AREA OF SINDH
}

\author{
Sameen Afzal Junejo, Nazir Ashraf Laghari and Farooque Ibrahim
}

\begin{abstract}
OBJECTIVE: To determine the prevalence of trachoma in a given population. DESIGN: A cross - sectional study.

SETTING: Department of Ophthalmology, Civil Hospital, Mirpurkhas - Sindh from January to December 2001.

METHOD: A total of four thousand (4000) patients of different age groups undergone a clinical examination of anterior eye during study period. Those with the clinical findings of trachoma underwent further detailed examination including visual acuity, tonometry and dilated ophthalmoscopy. The diagnosis of different stages of trachoma was confirmed clinically using simplified trachoma grading system of World Health Organization.

RESULTS: Out of 4000 patients, $515(12.87 \%)$ were found having clinical findings of trachoma. Among these, $215(41.74 \%)$ were male and 300 (58.25\%) female patients. The prevalence of active trachoma was higher in female children.

CONCLUSION: Trachoma has become endemic in the increasing poor population of District Tharparkar. The disease is increasing due to deficient water supply, poor sanitation and unhygienic living standards of the people of area.
\end{abstract}

KEY WORDS: Trachoma. Blindness. Prevalence. Pakistan.

\section{INTRODUCTION}

Trachoma is a communicable disease. It is a type of kerato-conjunctivitis that runs a chronic course and is the second leading cause of blindness in world ${ }^{1,2}$. The causative agent chlamydia trachomatis is spread by direct contact, dirt and flies. The ocular involvement in trachoma ranges from conjunctival follicles to trichiasis, corneal scarring, complete corneal opacity and blindness $s^{3,4}$. This infection is transmitted from eye to eye by hands, clothing and other fomites. Flies are the major vector for the spread of infection ${ }^{5}$. More than fifty-five countries have been identified as endemic for trachoma, most of them in Africa and Asia ${ }^{6}$. Trachoma frequently occurs in adult women ${ }^{7}$. Based on the clinical evidence of disease, World Health Organization (WHO) has introduced a simplified grading system for the assessment of trachoma ${ }^{8,9}$. It includes normal tarsal conjunctiva $(\mathrm{N})$, trachomatous follicle (TF), trachomatous intense inflammation (TI), trachomatous scarring (TS), trachomatous trichiasis (TT) and corneal opacity (CO). Regarding the prevalence of trachoma in different districts of Pakistan, detailed work has not yet been conducted. However, in some generally collected data within few districts, active trachoma has been found most common presentation $(2.4 \%)$ followed by trichiasis $(1.6 \%)^{10}$. Among afghan refugees in Northern Pakistan, active trachoma (TF and $\mathrm{TI}$ ) has been found in $3.7 \%$ of children under 10 years of age. However, the overall prevalence of active trachoma has been reported as $2.6 \%{ }^{11}$.

This study was designed to see the prevalence of trachoma in Thar desert area of Sindh.

\section{PATIENTS AND METHODS}

This cross-sectional study was carried out from January to December 2001. Local patients and those coming from different towns and villages of district Tharparkar were examined. The team of doctors consisted of two ophthalmologists, each accompanied by one senior medical officer already working at eye department of Civil Hospital, Mirpurkhas - Sindh and the other paramedical staff. All patients undergone a routine examination of anterior eye with binocular ophthalmic loupe $(2.5 \mathrm{X})$ and hand held light source. The patients having clinical findings of trachoma 
undergone further detailed examination i.e. visual acuity, tonometry, dilated ophthalmoscopy. The diagnosis of trachoma was confirmed on clinical assessment. Due to paucity of histopathological facilities at Mirpurkhas and its surroundings, the patients were diagnosed using simplified grading system of trachoma adopted by WHO. A total of four thousand (4000) patients were examined during study period.

\section{RESULTS}

Out of four thousand patients examined, 515 patients had clinical findings of trachoma. Children under the age of 12 years showed high prevalence of active disease with majority in females (Table I). Table II shows the prevalence in adult age group. In this group also, the female patients had the increased prevalence than male patients. Active trachoma (TF, TI) was present in180(34.95\%) male and 246 $(47.76 \%)$ female patients. The frequency of active trachoma was higher in children and young adults. However, the total number of patients with trichiasis and corneal opacities was critically lower (Table II). Trachoma in general and active trachoma in particular was found more prevalent in females as compared to male patients. Overall, the prevalence of trachoma in 4000 patients during study period was found as $12.87 \%$ (515 patients). Its prevalence in males was $41.74 \%$ (215 patients) and in females, it was $58.25 \%$ (300 patients). Findings based on clinical diagnosis of patients according to WHO grading system are presented in Table III.

TABLE I:

PREVALENCE OF TRACHOMA IN CHILDREN $(n=515)$

\begin{tabular}{|c|c|c|c|}
\hline $\begin{array}{c}\text { Age } \\
\text { (years) }\end{array}$ & Sex & $\begin{array}{c}\text { Number of } \\
\text { Patients }\end{array}$ & Prevalence \\
\hline $1-4$ & $\mathrm{M}^{*}$ & 20 & $03.88 \%$ \\
\hline $5-8$ & $\mathrm{M}$ & 55 & $10.67 \%$ \\
\hline $9-12$ & $\mathrm{M}$ & 40 & $07.76 \%$ \\
\hline
\end{tabular}

${ }^{*} \mathrm{M}=$ Male ${ }^{* *} \mathrm{~F}=$ Female
TABLE II:

DISTRIBUTION OF TRACHOMA IN ADULT PATIENTS

\begin{tabular}{|c|c|c|c|}
\hline $\begin{array}{c}\text { Age } \\
\text { (years) }\end{array}$ & Sex & $\begin{array}{c}\text { Number of } \\
\text { Patients }\end{array}$ & Prevalence \\
\hline $13-16$ & $\mathrm{M}$ & 18 & $03.49 \%$ \\
& & 26 & $05.04 \%$ \\
\hline $17-20$ & $\mathrm{M}$ & 13 & $02.52 \%$ \\
& 20 & $03.88 \%$ \\
\hline $21-24$ & $\mathrm{M}$ & 12 & $02.33 \%$ \\
& & 17 & $03.30 \%$ \\
\hline $25-28$ & $\mathrm{M}$ & 12 & $02.33 \%$ \\
& & 18 & $03.49 \%$ \\
\hline $29-32$ & $\mathrm{M}$ & 10 & $01.94 \%$ \\
& & 15 & $02.91 \%$ \\
\hline $33-36$ & $\mathrm{M}$ & 8 & $01.55 \%$ \\
& & 12 & $02.33 \%$ \\
\hline $37-40$ & $\mathrm{M}$ & 8 & $01.55 \%$ \\
& & 11 & $02.13 \%$ \\
\hline $41-44$ & $\mathrm{M}$ & 7 & $01.35 \%$ \\
& & 11 & $02.13 \%$ \\
\hline $45-48$ & $\mathrm{M}$ & 6 & $01.16 \%$ \\
& & 10 & $01.94 \%$ \\
\hline $49-52$ & $\mathrm{M}$ & 4 & $00.77 \%$ \\
& & 6 & $01.16 \%$ \\
\hline $53-56$ & $\mathrm{M}$ & 2 & $00.38 \%$ \\
& & 4 & $00.77 \%$ \\
\hline
\end{tabular}

TABLE III:

CLINICAL DIAGNOSIS OF PATIENTS ACCORDING TO WHO GRADING SYSTEM

\section{DISCUSSION}

\begin{tabular}{|c|c|c|c|}
\hline $\begin{array}{c}\text { WHO } \\
\text { Grade }\end{array}$ & Sex & $\begin{array}{c}\text { Number of } \\
\text { Patients }\end{array}$ & Prevalence \\
\hline TF, TI & M & 180 & $34.95 \%$ \\
\hline TS & M & 15 & $02.91 \%$ \\
\hline TT & M & 35 & $06.79 \%$ \\
\hline CO & M & 06 & $01.16 \%$ \\
\hline
\end{tabular}


Trachoma is a disease of poor communities living in developing countries and accounts for $15 \%$ of blindness worldwide. In this way, about 6 million people suffer from blindness due to trachoma ${ }^{12}$. According to WHO, currently, 84 million people mostly children have active disease and another 7.6 million people suffer from trichiasis, the stage of trachoma in which upper eye lid turns inwards and eye lashes rub against the eye ball ${ }^{12}$. In this study also, the prevalence of active trachoma was higher than the stage of complications i.e. trachoma $T$ (trichiasis). An estimated $10 \%$ of world's population lives in endemic areas and is more prone to develop trachoma ${ }^{13}$. This study was also designed in the population of Tharparkar desert area of Sindh which is most endemic area to trachoma. More than $90 \%$ of blindness from trachoma is found in developing countries and vast majority of problem is seen in rural areas of these countries like Tharparkar ${ }^{14}$. District Tharparkar is one of the remote areas of Sindh province where basic needs of life and water supply are quite scarce. In this study, females were found suffering more than the male individuals from trachoma. Possible reasons for it may be that in Tharparkar area, people are living in a very unhygienic atmosphere and women also have more contact with their children as compared to males. Over crowding, lack of water supply and amount of water used for washing purposes are the major sources for trachoma infection ${ }^{15}$. In trachoma, blindness results from corneal opacification related to the degree of trichiasis ${ }^{16}$ and in this study, 16 patients developed corneal opacities due to trichiasis. In quite a good number of studies performed elsewhere, it has been shown that the prevalence of trachoma decreases in those areas where people are trained to acquire the habit of proper face and hands washing ${ }^{17-19}$ and eliminating trachoma as a blinding disease should be the goal of community ophthalmologists through increasing the awareness of population by means of continued and related health education. The concerned health staff of community ophthalmology centers should also be trained properly to diagnose the disease and ensure provision of timely treatment. This is an unusual study regarding the prevalence of trachoma in District Tharparkar of Sindh province. This provides vital epidemiological data regarding higher prevalence of trachoma in this area as compared to local and international literature. This data can be highly beneficial for designing measures to control and eradicate the trachoma in Tharparkar.

\section{REFERENCES}

1. Johns $S$ and Fords $S$. Eye disease in hot climate. $2^{\text {nd }}$ edition. Oxford: ELBS, London,1990.

2. Thylefors B, Negrel AD, Dadzie KY. Global data on blindness. Bull World Health Organ1995;73:115-121.

3. Jones BR. The prevention of blindness from trachoma. Trans Ophthalmol Sol UK 1975; 95:16.

4. Tobbara KF. Chlamydial conjunctivitis, infection of the eye. $1^{\text {st }}$ edition. Boston, Little Brown, 1986.

5. Emerson PM, Lindsay SW, Alexander N, et al. Role of flies and provision of latrines in trachoma control. Lancet 2004;363:1093 - 1098.

6. Whitcher JP, Srinivasan M, Upadhyay MP. Corneal blindness, a global perspective. Bull World Health Organ 2001; 79: 214- 221.

7. Regassa K, Teshome T. Trachoma among adults in Damot Gale District, South Ethiopia. Ophthalmic Epidemiol 2004;11: 9 - 16.

8. Thylefors B, Dawson CR, Jones BR, et al. A simple system for the assessment of trachoma and its complications. Bull World Health Organ 1987;65:477 - 483.

9. Munoz B, West S. Trachoma: the forgotten cause of blindness. Epidemiol Rev 1997; 19: 205 - 217.

10. Qureshi MB, Khan MD, Khan MA. Current status of trachoma. Pak J Ophthalmol 1998;14 (4):165 171.

11. Awan HR, Ahsan T. Prevalence of visual impairment and eye diseases in Afghan refugees in Pakistan. East Mediter Health J 1998;4(3):560 -566 .

12. World Health Organization. Report of eighth meeting of WHO Alliance for the global elimination of trachoma. Geneva: World Health Organization; 2004:29 -31.

13. Frick KD, Hanson CL, Jacobson GA. Global burden of trachoma and economics of the disease. Am J Trop Med Hyg 2003;69:1 - 10.

14. Suka TY, MWandu DH and Negalande TC. Prevalence of blindness and visual impairment in 
Luapual Valley, Zambia. Trop Geogr Med J 1988; $27-40$.

15. Prost A, Negrel AD. Water, trachoma and conjunctivitis. Bull World Health Organ 1989;76:9 $-18$.

16. West SK. Trachoma: new assault on an ancient disease. Prog Retin Eye Res 2004;23:381 - 401.

17. De Sole G. Eye diseases. In Zein AZ and Kloosh, eds. The Ecology of Health and disease in
Ethiopia.1993;239 - 243.

18. West S, Munoz B, Lynch M, et al. Impact of face washing on trachoma in Kongwa, Tanzania. Lancet 1995;345(8943):155 - 158.

19. Lynch M, West S, Mumoz B, et al. Testing a participatory strategy to change hygiene behavior: face washing in Central Tanzania. Trans R Soc Trop Med Hyg 1994; 88(5): 513 - 517.

\author{
AUTHOR AFFILIATION: \\ Dr. Sameen Afzal Junejo (Corresponding Author) \\ Assistant Professor of Ophthalmology \\ Liaquat University Eye Hospital Hyderabad and \\ Liaquat University of Medical and Health Sciences \\ (LUMHS) Jamshoro - Sindh. \\ Prof. Nazir Ashraf Laghari \\ Department of Ophthalmology \\ Liaquat University Eye Hospital Hyderabad and \\ LUMHS Jamshoro - Sindh. \\ Dr. Farooque Ibrahim \\ Incharge Ophthalmologist \\ Civil Hospital Mirpurkhas - Sindh.
}

